\title{
The role of demographics on adolescents' preferences for risk, ambiguity, and prudence
}

\author{
Kim Fairley ${ }^{\mathrm{a}, \mathrm{b}, *}$, Alan G. Sanfey ${ }^{\mathrm{b}, \mathrm{c}}$ \\ a Institute of Tax Law and Economics, Department of Economics, Leiden University, Leiden, the Netherlands \\ ${ }^{\mathrm{b}}$ Donders Institute for Brain, Cognition and Behaviour, Radboud University Nijmegen, PO Box 9101, 6500 HB Nijmegen, the Netherlands \\ ${ }^{\mathrm{c}}$ Behavioural Science Institute, Radboud University Nijmegen, PO Box 9101, 6500 HB Nijmegen, the Netherlands
}

\section{A R T I C L E I N F O}

\section{Article history:}

Received 7 February 2018

Revised 28 February 2020

Accepted 20 March 2020

Available online 16 June 2020

\section{JEL codes:}

C91

C93

D81

D91

Keywords:

cognitive ability

non-cognitive ability

adolescence

risk

ambiguity

prudence

\begin{abstract}
A B S T R A C T
Given adolescents' propensity to engage in risky activities, experimentally elicited risk preferences have received much attention in this demographic group. In order to address the likelihood of engaging in potentially harmful activities, this study investigates various correlates of adolescents' risk preferences. Few studies have looked at other dimensions of decision-making under uncertainty in this important population, and here we attempted to close this gap by conducting a "lab in the field" experiment with adolescents. Our goals were twofold. First, we assessed both standard risk preferences during adolescence, as well as those of ambiguity and the higher order concept of prudence. Second, we examined the influence of individual characteristics of the decision-maker on attitudes towards risk, ambiguity, and prudence. In addition to gender and age, we focused on cognitive and noncognitive abilities as potential moderators of interest Our results demonstrated that adolescents are risk neutral on average, however they are also typically ambiguity averse and display prudent behavior. Also, we found that various individual factors influenced adolescents' attitudes towards risk, ambiguity, and prudence. These specific characterizations can greatly aid in targeting policy in adolescence, and we conclude by suggesting several possibilities for these interventions.
\end{abstract}

(c) 2020 Elsevier B.V. All rights reserved.

\section{Introduction}

More frequently than with any other age group, adolescents ${ }^{1}$ engage in risky and potentially harmful activities such as drinking, smoking, unprotected sex, criminal activity, and reckless driving (Steinberg, 2004; Blum and Nelson-Mmari, 2004; Williams et al., 2002), and, not surprisingly, adolescents have been shown to be more risk tolerant than adults in many experimental studies (e.g. Harbaugh et al., 2002; Levin and Hart, 2003, Defoe et al., 2015). If we wish to target policy initiatives to those adolescents who are most likely to engage in potentially dangerous activities, it is therefore essential to pinpoint who exactly is at risk. For instance, there is ample evidence from laboratory studies that boys are more risk tolerant than girls (Sutter et al., 2019), and indeed the young mortality hump - 'a temporary deviation of the aggregated age-specific death rate from the exponential trend' (Human mortality database, 2017) - is much stronger for boys than girls

\footnotetext{
* Corresponding author at: Department of Economics, Leiden University, Steenschuur 25, 2311 ES Leiden, the Netherlands. Tel.: +31 (0)71 5273885

E-mail address: k.fairley@law.leidenuniv.nl (K. Fairley).

1 Typically, the age range of adolescence is defined as between 10 and 19 years (World Health Organization, 2014). In this study we focus on the age range of 12-17 years as this study was conducted at a high school. When we refer to adolescence in this study, we refer to this particular age range.
} 
(Remund et al., 2018). In this vein, behavioral profiles as to which particular groups of adolescents are most likely to engage in harmful, risky, activities could be usefully employed for highly targeted mentorship programs, e.g. to reduce shootings as suggested in Chandler et al. (2011). To make steps towards achieving this societally important goal, and in an effort to pinpoint at-risk adolescents, this study examines the relationship between certain individual variables and three particular characterizations of decision-making preferences under uncertainty, namely risk, ambiguity, and prudence. We examine these attitudes in a lab-in-the-field experiment with adolescents (aged 12 to 17) at a high school in the Netherlands.

In regards to the measures of risk that we explore here as laboratory proxy for adolescents' propensity to engage in risky activities, simply using standard measures such as basic risk preferences is somewhat limiting given the complexity of how 'risk' can be understood. Hence, we sought to broaden this examination by also focusing on attitudes towards ambiguity and prudence. To define the former, choices made under conditions of unknown probabilities have typically been labeled as 'ambiguous' (Keynes, 1921; Knight, 1921). Many everyday choice scenarios have this flavor, where we do not know the explicit underlying probabilities. For example, a teenager riding a motorbike without a helmet does not know the exact likelihood that she will have a road accident and incur severe head injuries. For the first additional variable therefore, we examine attitudes toward ambiguous risks. For the second novel exploration, we measure prudence. The concept of prudence captures the notion that we change our decision behavior as a function of the background risk that we perceive (Kimball, 1990). A prudent decision-maker responds to increases in background risk by increasing precautionary savings, and this attitude has been shown to have theoretical and empirical links with decision domains such as financial, schooling and employment choices (Noussair et al., 2014; Browning and Lusardi, 1996), though not to date for adolescents. As these decision domains are also relevant for adolescents, we examine here how prudence is reflected in this particular age group. When it comes to schooling choices, adolescents are already required to select and drop certain school courses during high school, which guarantees entree to particular study fields, but restricts future career options as well. ${ }^{2}$ Furthermore, adolescents will face tradeoffs in managing their own budget for the first time in their lives. ${ }^{3}$

In terms of the individual measures that are potentially related to the risk variables described above, gender and age are standard demographic indicators to consider as a first, rather general, effort in characterizing adolescents prone to undertake risky activities. However, recently there has been increasing awareness of the relevance of particular cognitive and non-cognitive abilities, also referred to as personality traits, in their predictive power of future life outcomes. Empirical research shows that both IQ scores and non-cognitive abilities such as perseverance and conscientiousness predict educational attainment, health levels, and criminology (Almlund et al., 2011; Borghans et al., 2008; Kautz et al., 2014). Importantly, these traits are somewhat flexible during adolescence, as evidenced by successful interventions to promote more favorable personality characteristics during this age (Heckman and Mosso, 2014; Kautz et al., 2014), and therefore these measures are useful to assess as potential intervention points. Therefore, here, in addition to age and gender, we also examine both cognitive and non-cognitive abilities in terms of their relationship to various aspects of risk.

IQ scores, school grades, cognitive tests such as the Cognitive Reflection Test (Frederick, 2005), and achievement tests are widely used as proxies for cognitive ability (Borghans et al., 2016). Although these proxies are typically well correlated, the measures do differentially predict a variety of important life outcomes. For instance, Borghans et al. (2016) show that school course grades are more predictive of life outcomes, such as wages, BMI, and number of arrests, than is IQ as grades capture aspects of personality that have independent predictive power. Non-cognitive abilities are often measured with a questionnaire such as the Big Five personality inventory (Borghans et al., 2008). ${ }^{4}$ Not surprisingly, cognitive and noncognitive abilities are interrelated: a student who is motivated and conscientious will take tests more seriously and will likely have higher school grades (Borghans et al., 2016). However, to take advantage of the differing predictive power of the various measures outlined above, here we take several assessments of (non-)cognitive abilities into account. The high school administration provided us with pupils' mathematics and Dutch language grades, their IQ scores (Liepmann et al., 2007) and self-reported responses to a personality test (Smits and Vorst, 2008), which measured motivation, self-confidence and well-being, and we additionally measured our participants on the Cognitive Reflection Test (Frederick, 2005).

Previous work has provided indication that various measures of cognitive ability are positively related to both risk aversion (Dohmen et al., 2010) and prudence (Noussair et al., 2014; Breaban et al., 2016), though typically examined in adults. These relationships in adolescence have received little attention thus far, despite the evident promise in identifying at-risk adolescents. The aim of this study is therefore to explore these interrelationships in more detail and contribute to the sparse literature on risk, ambiguity, and prudence in adolescence.

The basic question if adolescents are ambiguity averse - as often found in adults - is still to date unclear. Tymula et al. (2012) and Li et al. (2015) describe adolescents and children as ambiguity tolerant, whereas, in contrast, Sutter et al. (2013) and Borghans et al. (2009) demonstrate ambiguity aversion in adolescence. Differences in these results can likely be

\footnotetext{
2 During third grade of high school (14-15-year-olds), Dutch adolescents choose a 'school profile' which consists of a selection of school courses. For example, the school profile 'Nature and Health' consists of biology, physics and chemistry and gives access to medical school, whereas other school profiles such as 'Economics and Society' consists of Economics, Geography and History and does not typically provide access to medical school. Therefore, an errant choice dramatically limits future career options.

3 A twelve year old has on average $€ 22$ to spend monthly, whereas an eighteen year old already has a monthly budget of $€ 206$. Half of all 12 -18-year-olds use online banking to purchase items such as food, clothing, a cell phone and games (National Institute for Budget Information, 2016).

4 These five personality traits are experience to openness, conscientiousness, extraversion, agreeableness and neuroticism. See Borghans et al. (2008) and Almlund et al. (2011) for an overview of this literature in the context of economics.
} 
ascribed to the respective elicitation tasks: Tymula et al. (2012) and Li et al. (2015) used a mix of known and unknown information and thus participants were introduced to partial ambiguity, whereas Sutter et al. (2013) exposed participants to complete uncertainty. We elicited risk and ambiguity preferences via a standard Ellsberg lottery setup (Ellsberg, 1961), so participants faced complete uncertainty as in Sutter et al. (2013).

Except for one working paper on the transmission of risk preferences and prudence between children and their parents (Heinrich and Shachat, 2018), prudence has not been investigated in adolescence ${ }^{5}$. While relatively few experimental studies have elicited prudence in participants, all have reached the same conclusion: people are generally prudent (Tarazona-Gomez, 2004; Deck and Schlesinger, 2010; 2014, Ebert and Wiesen, 2011, Maier and Rüger, 2011, Noussair et al., 2014, Breaban et al., 2016; Haering et al., 2017; Ebert and van der Kuilen, 2017). As the first investigation of prudence in adolescence, we will examine if prudence is indeed a measurable construct that is already present at this age. In this study, we elicit prudence via the model-free measurement approach of Eeckhoudt and Schlesinger (2006).

In the next section we review the literature on the interrelationships of the demographic variables age, gender, cognitive and non-cognitive abilities and adolescents' attitudes towards risk, ambiguity and prudence. Then we will outline our research design and the specifications of our experimental tasks as well as the measures provided to us by the high school administration. Following the methods section, we will present our results. First we will report adolescents' attitudes towards our three indicators of decision-making under uncertainty before we will investigate its relationship with our demographic variables. Finally, we will discuss our findings and offer recommendations on how demographic variables can aid in determining which adolescent is prone to undertake risky activities.

\section{Related literature and hypotheses}

Gender and age effects on decision-making under uncertainty have been documented quite frequently. The literature on the relationship between cognitive and non-cognitive abilities and decision-making under uncertainty in adolescence is however quite sparse. Below, we outline several studies and their findings on this topic. For a complete overview, all referenced literature on adolescence can be found in Table A1 in the Appendix. Based on the findings from adult studies and those few previous findings in adolescence, we specify our hypotheses.

\subsection{Gender}

There is a strong indication that girls are significantly more risk averse than boys (e.g. Sutter et al., 2013, 2019; Levin and Hart, 2003; Borghans et al., 2009; Cardenas et al., 2012). These results were found in a range of children from 4 years of age until late in adolescence (Sutter et al., 2019). Ambiguity preferences between girls and boys do not seem to differ however (Sutter et al., 2013; Borghans et al., 2009; Tymula et al., 2012). With regard to prudence, most studies in adults and Heinrich and Shachat's paper in adolescence, point towards an absence of gender effects (Trautmann and van de Kuilen, 2018; Noussair et al., 2014, Deck and Schlesinger, 2014).

Based on this evidence, we hypothesize that boys are more risk tolerant than girls, but both groups show similar attitudes towards ambiguity and prudence.

\subsection{Age}

Several studies with young children have reported age effects on risk preferences, with risk tolerance decreasing with age (Harbaugh et al., 2002; Deckers et al., 2015). However, on the other hand, Levin et al. (2007) compared risky choices made by 9-11-year-olds to their choices three years later and did not find any age effects on risk aversion. In adolescents, most studies have not found any age effects on risk (Sutter et al., 2019; 2013, Eckel et al., 2012; Munro and Tanaka, 2014), ambiguity $^{6}$ (Sutter et al., 2013), nor prudence (Noussair et al., 2014). Heinrich and Shachat (2018) showed a significant effect of school grade on prudent behavior, implying that prudence increased with age, but as the school type and level were not consistent over their sample, Trautmann and van de Kuilen (2018) indicated in their review on higher-order risk attitudes that these results should be interpreted with caution.

Based on our sample of 12 to 17-year-olds, we hypothesize that age has no effect on any of the three economic behaviors of interest during adolescence.

\subsection{Cognitive ability}

In adults, several studies (Dohmen et al., 2010; Falk et al., 2018) have shown that lower cognitive ability was related to greater levels of risk aversion. In adolescents however, the effects of cognitive ability on risk preferences are quite mixed.

\footnotetext{
5 Although most studies on prudence (Tarazona-Gomez, 2004; Deck and Schlesinger, 2010; 2014, Ebert and Wiesen, 2011, Maier and Rüger, 2011, Noussair et al., 2014) used student samples, which partly also consist of 18-19-year-olds. Our study and the working paper by Heinrich and Shachat (2018) used an exclusive sample of adolescents.

${ }^{6}$ Li et al. (2015) and Tymula et al. (2012) compared children (8-9-year-olds in Li et al., 2015) and adolescents (12-17-year-olds in Tymula et al., 2012) to an adult sample and both found that ambiguity aversion peaked in adults, but did not study the effect of age during adolescence.
} 
Table 1

Experimental sample.

\begin{tabular}{lllll}
\hline Class & N & Girls/Boys & Age range & Risk/Ambiguity order \\
\hline 2D & 28 & $14 / 14$ & $12-14$ years & Ambiguity first \\
2G & 22 & $13 / 9$ & $12-14$ years & Risk first \\
3C & 23 & $12 / 11$ & $13-16$ years & Risk first \\
3D & 21 & $8 / 13$ & $13-15$ years & Ambiguity first \\
4A & 24 & $13 / 11$ & $14-17$ years & Risk first \\
4E & 14 & $7 / 7$ & $15-17$ years & Ambiguity first \\
5B & 19 & $9 / 10$ & $15-17$ years & Risk first \\
5F & 21 & $7 / 14$ & $16-17$ years & Ambiguity first \\
\hline
\end{tabular}

Benjamin et al. (2013) found that high-school students with higher math grades made more risk neutral choices, whereas Eckel et al. (2012) and Sutter et al. (2013) did not find any relationship between math grades and risk aversion in adolescence. Consistently, cognitive ability and ambiguity preferences do not seem to be related (Sutter et al., 2013; Borghans et al., 2009; Tymula et al., 2012). However, there is some evidence that cognitive ability, or higher education in the general population, is related to prudence, at least in adults (Noussair et al., 2014; Breaban et al., 2016).

Based on the evidence in adults, we therefore hypothesize that the cognitive ability of adolescents is related to prudence, but not to risk and ambiguity.

\subsection{Non-cognitive ability}

Based on a handful of studies on the relationship between non-cognitive ability and decision-making under uncertainty, the personality trait of neuroticism seems to correlate with risk aversion, but not with ambiguity aversion, in both adults and adolescents (Rustichini et al., 2016; Becker et al., 2012; Borghans et al., 2009; Tymula et al., 2012). With regard to prudence, we are unaware of any study in relation to non-cognitive abilities. However, some researchers have labelled prudence as a universal trait (Crainich et al., 2013). If this is the case, subtle nuances in prudent attitudes may not relate to personality traits.

Neuroticism is defined as a chronic level of emotional instability and proneness to psychological distress (Borghans, 2008). From the personality questionnaire conducted by the high school we investigated for this study, the concept of selfconfidence comes closest to that of neuroticism. This concept measured three sub-domains which captured a participant's ability to express oneself, confidence in taking exams, and confidence in social skills.

Based on the findings presented here, we hypothesize that participants' self-confidence, as a feature of their non-cognitive abilities, is related to risk in adolescents, but not to ambiguity and prudence.

\section{Experimental design and procedures}

\subsection{Participants}

We conducted this paper and pencil experiment with 187 adolescents at a high school in Nijmegen, the Netherlands. In the Netherlands, there are three levels of higher education with this school belonging to the highest level. The local ethics committee approved this study, which took place over one week.

Two classes per school-year were randomly selected, with participants' age ranging from 12-17 years. See Table 1 for a breakdown of the selected classes. We excluded both the first and the last school-years as the former had been very recently exposed to the intelligence test and psychological measures, and the latter were preparing for their final school exams. We organized the experiment during regular school hours in the 'mentor class'. This is a weekly class hour in which the class mentor informs students about school news and discusses general school matters.

The mentors of the selected classes informed the students' parents about the upcoming experiment via an information letter. In order for their child to participate, parents were required to return a signed statement (i.e. opt-in consent was utilized). At most one or two pupils from each class were not present during testing time due to illness or parents' nonapproval.

In total, we tested 187 participants during regular school hours. There were missing data from 15 participants, and so these were excluded from our sample. ${ }^{7}$ Therefore, a total of 172 participants ( 83 girls and 89 boys) remained. Results are reported from these 172 participants.

\footnotetext{
7 There was no missing observations regarding the experimentally collected data, but the school could not provide the questionnaire data if children had enrolled in the school after the first year of high school.
} 


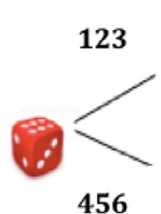

456
Option A

$€ 3$

$€ 4.50$

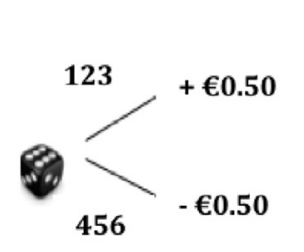

0

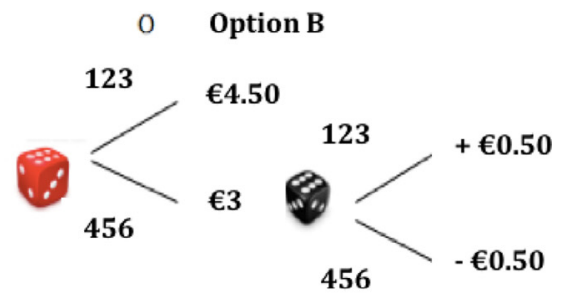

Fig. 1. Example decision problem prudence measurement.

\subsection{Experimental design}

Participants completed experimental tasks in their classroom. First, we elicited risk and ambiguity preferences, followed by an assessment of their beliefs regarding the ambiguous prospect. Then, we estimated parameters for prudence. ${ }^{8}$ Finally, participants completed the three questions of the cognitive reflection test (Frederick, 2005). Instructions were written in Dutch (see Appendix for a translated version and details on our procedures) and all participants received a handout of these instructions.

\subsubsection{Risk and ambiguity}

We elicited risk and ambiguity preferences via a multiple-choice list procedure, as per Sutter et al. (2013). In our Ellsberginspired version (Ellsberg, 1961) there were two bags, which were both filled with 20 ping-pong balls. One bag, the risky prospect, was filled with exactly 10 orange and 10 white ping-pong balls. The other bag, the ambiguous prospect, was filled with an unknown composition of white and orange ping-pong balls. In both the risky and ambiguous multiple-choice lists, participants made 20 choices between a gamble and a sure pay-off, with the latter increasing in size after each choice (the range was from 0 to 5 Euro in 20 steps of 0.25 Euro). A gamble in this setting meant that a participant would draw a pingpong ball from a bag, and would win 5 Euro if this ping-pong ball matched the color she had selected beforehand. If not, she would win nothing. Namely, before instructions, participants could choose their own winning color in order to eliminate any suspicion that the likelihood of a win/loss from the ambiguous bag may have been predetermined (Wakker, 2010). We measured when participants switched from the gamble to the sure pay-off. The later they switched to the sure pay-off, the more they were willing to gamble, and therefore the less they expressed risk averse and ambiguity averse behavior. The order of choosing the risky and ambiguous prospects was counterbalanced across different school classes to control for any potential order effect (see Table 1).

After participants made their decisions for the ambiguous prospect, we elicited their beliefs regarding the composition of the ambiguous bag. Specifically, we asked them to indicate how many ping-pong balls of their selected color they thought were present in the ambiguous bag. Given a total of 20 ping-pong balls in the ambiguous bag, each of which is one of two possible colors, the objective underlying likelihood of drawing a ping-pong ball that matches participants' selected color is 0.5. Therefore, any reported difference from 10 balls indicated a deviation from an ambiguity neutral state.

\subsubsection{Prudence}

We estimated preferences for prudence via a set of decision problems that do not require any axiomatic assumptions concerning the utility function. Specifically, we elicited a measure of the construct of prudence using a model-free method that defines prudence as a preference for adding a lottery with a mean of zero to a state in which income is high, rather than adding it to a state in which income is low (Eeckhoudt and Schlesinger, 2006; Noussair et al., 2014). Essentially, prudent decision-makers do not want to bear two harms simultaneously, that is, both a certain loss and a risky lottery (Baillon, 2017). See Figure 1 for an illustration of the choice setup.

The original monetary amounts used in this task were scaled down to more appropriate amounts for adolescents. In this example (Figure 1) the decision maker faces two problems, the possibility of winning less (a reduction of wealth by 1.50 Euro) if the roll of the die is less than four in Option A (or three in Option B) and the possibility of facing a zero-mean lottery if the roll of the die is more than three in both options (in which case the roll of the second independent black die will determine the eventual outcome). A prudent decision-maker prefers to disaggregate both harms (Rothschild and Stiglitz, 1970), and therefore would opt for Option A.

The five decision problems presented to participants were similar in structure to Fig. 1, but varied in terms of the initial endowment and the wealth reduction (lottery attached to the red dice in Figure 1), as well as the size of the zero-mean lottery (lottery attached to the black dice in Figure 1). Following standard convention, each participant received a prudence score based on the number of prudent choices made (Trautmann and van de Kuilen, 2018). A score of 0 denoted extreme

\footnotetext{
${ }^{8}$ After eliciting prudence, we also measured loss aversion based on the choice list procedure developed by Fehr and Goette (2005). We scaled down the original monetary amounts to appropriate amounts for our experimental sample. It was hypothesized that cumulative prospect theory (Tversky and Kahneman, 1992) could explain behavioral patterns of prudence (Ebert and Wiesen, 2014; Deck and Schlesinger, 2010), however this is not part of the aims of this research study.
} 
imprudence, whereas a score of 5 represented extremely prudent behavior. We assessed the level of prudence in our population by comparing prudence scores to 2.5 , which indicates indifference (Noussair et al., 2014).

\subsubsection{Demographic data}

The high school provided us additional data regarding the participants in our study. We guaranteed complete anonymity in this experiment in the following way. Each participant listed their school ID number on their set of instructions. On the basis of this ID number the school provided the individual participant's data. The link between ID number and participant's identity was unknown to us, and additionally the school did not receive our experimental data.

We received basic demographic data, such as age and gender, and also received participants' grades for all courses as listed on their most recent semester report. Moreover, the high school provided scores on a set of validated intelligence tests and psychological measures. All pupils take these tests in their first year of high school, with pupils that score above average on the intelligence test offered an extra-curricular program. Pupils who score low on psychological measures like self-confidence are offered specific training or individual support from their class mentor. These tests are therefore taken very seriously by the school, are assessed by a pedagogical worker, and the scores are independently processed by a third party.

The school uses the 'IST Intelligence Structure Test' (Liepmann et al., 2007), which provides a score for six subdomains of intelligence, namely: general intelligence, memory, general development, verbal intelligence, numerical intelligence, and abstract intelligence, as well as a total average score of intelligence. We used the average score as our main variable of interest and refer to it as 'IQ score'.

We administered the cognitive reflection test (CRT; Frederick, 2005) as another proxy for cognitive ability. This test contains three questions, which proxy cognitive capabilities. For instance, one such question is the following: a bat and a ball together cost 1.10 Euro in total. The bat costs 1 Euro more than the ball. How much does the ball cost? An intuitive tendency is to answer with 0.10 Euro, however the correct answer is 0.05 Euro. Following standard conventions, each participant received a score between 0-3 depending on the amount of correct answers.

Finally, we use participants' grade for mathematics and Dutch (native language) as proxies for cognitive ability.

The personality test administered by the high school is a validated questionnaire of 160 statements in which pupils have to rate the extent to which the posed statements are similar to their character/behavior (Smits and Vorst, 2008). The questionnaire is related to pupils' school environment, and therefore elicits psychological measures within their school setting. The outcome of the questionnaire is a score on three domains, namely self-confidence, well-being, and motivation, with these domains divided into sub-domains. For self-confidence, these sub-domains are the ability to express oneself, confidence in taking exams, and confidence in their social skills. For well-being, the sub-domains are whether pupils enjoy school, feel accepted at school, and how they value the relationship with their teachers. The difference between these components is, for instance, that in the former a pupil feels accepted by peers, but is nevertheless very uncertain about her social skills, or vice versa. Finally, motivation is captured by study focus, concentration in the classroom, and attitude towards homework. In our analyses we used the overall scores for self-confidence, well-being, and motivation as personality measures. In a separate questionnaire (Lehwald, 1985), the school also elicits students' willingness to work hard (referred to as 'work hard' in the results section). This concept consists of the subdomains cognitive willingness to work hard, willingness to gather knowledge independently and competitive orientation.

\section{Results}

\subsection{Experimental variables}

\subsubsection{Risk, ambiguity and beliefs}

We followed the same procedure as Sutter et al. (2013) by using participants' switching point in the risk and ambiguity multiple-choice list to define certainty equivalents (CE). In contrast to Sutter et al. (2013), we did not remove participants who switched more than once. In this situation, we took the midpoint of several switch points. ${ }^{9} C E_{r}$ and $C E_{a}$ denote the certainty equivalents of the risky prospect and the ambiguous prospect respectively. Subsequently, risk and ambiguity preferences were determined based on CE (Wakker, 2010; Sutter et al., 2013). The parameter $r$ captures the degree of risk taking.

$$
r=1-C E_{R} / 5
$$

A value of $\mathrm{r}$ larger (smaller) than 0.5 indicates risk averse (risk seeking) behavior. A score of 0.5 denotes risk neural behavior. The parameter $r$ serves as the dependent variable for participants' risk attitude.

\footnotetext{
911 percent $(\mathrm{n}=19)$ of our participants switched more than once from the gamble to the sure option in either the risky or ambiguous prospect. This number is higher than in Sutter et al. (2013, 3 percent of multiple switchers in their adolescent sample) but much lower than $25 \%$ of inconsistent choices in Cardenas et al. (2012). Compared to adult samples, this percentage is very comparable (Becker et al., 2012; Hogarth and Villeval, 2014). As multiple switches could indicate misunderstanding, we include multiple switchers as a categorical variable to our regression models and we re-ran all our main analyses on the sample of participants who only switch once.
} 
Table 2

Descriptive statistics

\begin{tabular}{llllll}
\hline Variables & Sample & Mean & Std. dev. & Min & Max \\
\hline Experimental variables & Full & & & & \\
Ambiguity & 172 & 0.036 & 0.128 & -0.84 & 0.36 \\
Risk & 172 & 0.504 & 0.124 & 0.025 & 0.95 \\
Beliefs & 172 & 10.262 & 3.130 & 2 & 16 \\
Prudence & 172 & 3.843 & 1.317 & 0 & 5 \\
Cognitive abilities & & & & & \\
CRT & 172 & 1.977 & 0.979 & 0 & 3 \\
QQ score & 172 & 96.76 & 14.67 & 60 & 139 \\
Mathematics grade & 172 & 6.785 & 1.24 & 4 & 10 \\
$\begin{array}{l}\text { Dutch grade } \\
\text { Non-cognitive abilities }\end{array}$ & 172 & 6.837 & 0.829 & 5 & 9 \\
Self-confidence & 172 & 61.31 & 8.18 & 35 & 72 \\
Motivation & 172 & 61.33 & 9.38 & 31 & 72 \\
Well-being & 172 & 66.06 & 5.22 & 46 & 72 \\
Work hard & 172 & 22.84 & 5.69 & 5 & 36 \\
\hline
\end{tabular}

Individual ambiguity preferences are estimated as follows:

$$
a=\left(C E_{R}-C E_{A}\right) /\left(C E_{R}+C E_{A}\right)
$$

The difference between $C E_{r}$ and $C E_{a}$ is divided by the absolute level of the $C E$ of risk and ambiguity in order to control for the fact that similar differences in $\mathrm{CE}$ will weigh more heavily for a risk averse participant than for a risk neutral or risk seeking participant (Sutter et al., 2013). This parameter $a$ ranges from -1 (extreme ambiguity seeking) to 1 (extreme ambiguity aversion). A score of 0 indicates ambiguity neutrality. The parameter $a$ serves as the dependent variable for participants' ambiguity attitude.

In principle, utility models for risk and ambiguity can be calibrated from the observed switching points. As the practice of quantifying risk preferences by the curvature of the utility function alone is likely to be inappropriate for many decisionmakers (Pedroni et al., 2017), we decided to study preferences in terms of the raw switching points in a model-free way to avoid any confounding effects due to (arbitrary) parametric assumptions.

On average, our experimental population was risk neutral (mean $r$ value of 0.504 (not significantly different from 0.5: $p=0.689$, Wilcoxon signed-rank test, two-tailed), and ambiguity averse (mean $a$ value of 0.036 , which is significantly different than 0: $p<0.001$, Wilcoxon signed-rank test, two-tailed). See Table 2 for an overview of these descriptives.

On average, adolescents' beliefs were in line with the ambiguity neutral probability, as they estimated 10.26 winning colored ping-pong balls in the ambiguous bag (see Table 2 ), which was not significantly different from 10 ( $p=0.262$, Wilcoxon signed-rank test, two-tailed).

Finally, risk and ambiguity preferences were significantly negatively correlated ${ }^{10}$ (Pearson's $r=-0.268, p=<0.01$, see Table A2 in the Appendix).

Result 1: On average, adolescents were risk neutral, ambiguity averse, and held beliefs in line with ambiguity-neutral probability.

\subsubsection{Prudence}

On average, participants made 3.843 prudent choices (see Table 2). This value significantly exceeds $2.5(p<0.001$, Wilcoxon signed-rank test, two-tailed), which demonstrates prudent behavior in adolescence.

In contrast to evidence stemming from adult samples, prudence and risk were unrelated in adolescents: for all levels of risk aversion, participants are prudent (see Figure 2). Finally, prudence was also unrelated to ambiguity.

\section{Result 2: Adolescents were prudent for every level of individual risk.}

\subsubsection{Cognitive abilities}

Our participants scored an average of two correct questions in the CRT, and had a mean IQ score of 96.76. The mean mathematics grade and Dutch grade are 6.78 and 6.84 respectively, which correspond to a $\mathrm{B}^{-}$according to the US grading system. Although our participants were at the highest level of high school in the Netherlands, there is still a wide variety of cognitive abilities as can be seen by the standard deviation of all four variables.

\footnotetext{
${ }^{10}$ Most studies report positive correlations between risk and ambiguity preferences (Trautmann and van de Kuilen, 2015), but it is interesting to note that those studies that employed the same elicitation procedure as was done here also reported negative correlations between risk and ambiguity (Sutter et al., 2013; Akay et al., 2012; Cubitt et al., 2012). This can be explained by our definition of ambiguity preferences as a normalized difference between the CE of the risky prospect and the CE of the ambiguous prospect. A maximally risk averse subject cannot be ambiguity averse in this setup (Trautmann and van de Kuilen, 2015, p. 109) and this could lead to no or negative correlation between risk and ambiguity preferences. Therefore, we do not discuss this correlation in much depth here.
} 


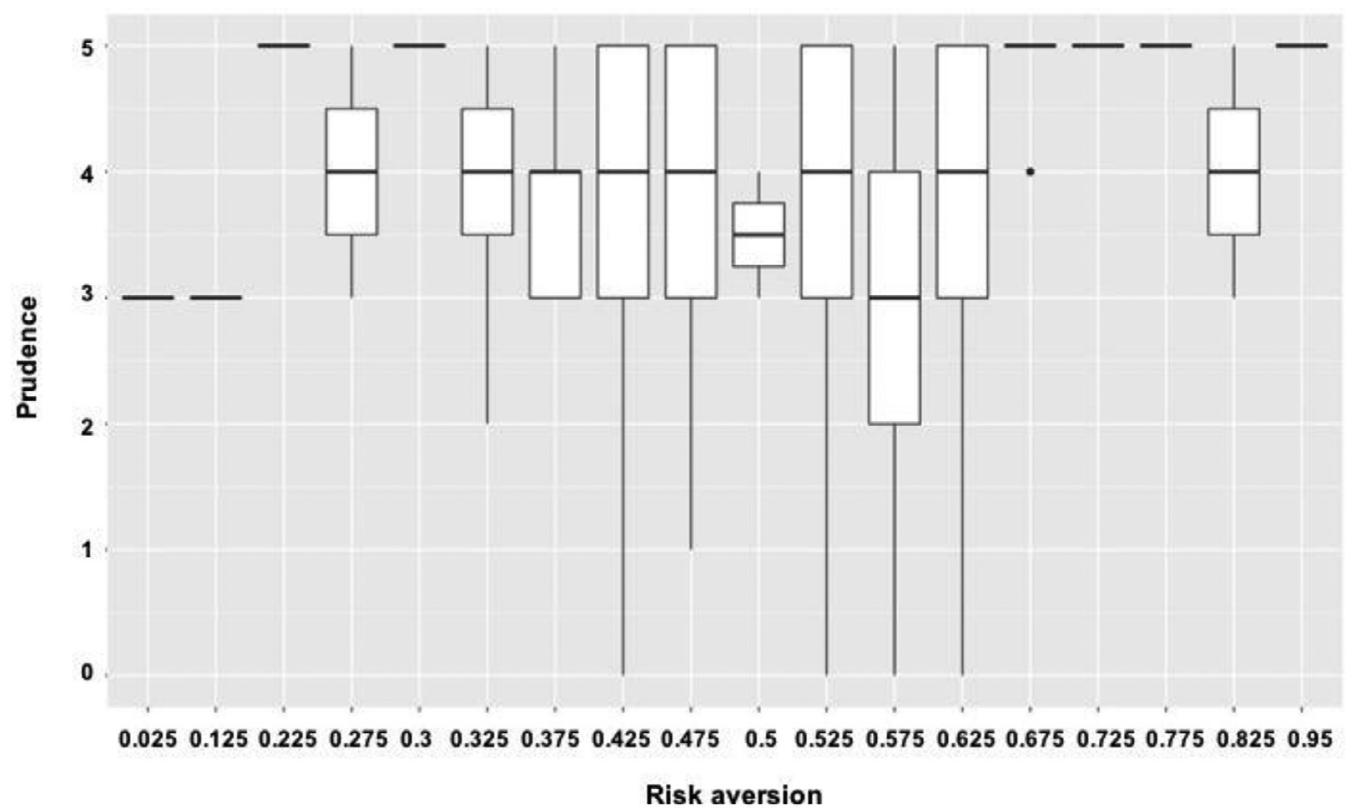

Fig. 2. At every level of risk (indicated by the value $r$ ), a boxplot indicates participants' level of prudence (indicated by the number of prudent choices). A single line indicates there was only one person with this level of risk aversion. Single dots indicate outliers. This image indicates that prudence and risk aversion are unrelated in adolescence

As expected, there was a high correlation between the different measures that capture degrees of cognitive abilities; the overall IQ score, the scores on the CRT and pupil's mathematics and Dutch grade were all positively correlated (see Table $\mathrm{A} 2$ in the Appendix).

\subsubsection{Non-cognitive abilities}

Participants can score maximum 72 points on each of the non-cognitive scales, except for "hard work" which has a maximum score of 41 . Although some participants score relatively low (see minimum scores in Table 2), on average pupils are motivated, are doing well, are self-confident and are willing to work hard. With the exception of the relationship between self-confidence and hard work, all indices are inter-related, which suggest that they capture a general non-cognitive ability. Participants' non-cognitive abilities are significantly related to their mathematics grade and IQ score as well (see Table A2 in the Appendix), except for scores on the CRT. These relationships indicate the importance of motivation, well-being, and self-confidence to school performance.

\subsection{Influence of demographic characteristics}

\section{Gender and age}

Girls and boys did not differ in their risk and ambiguity preferences (see Table 3). With regard to prudence, boys and girls also did not significantly differ from each other. There were notable gender differences regarding beliefs, and therefore it is surprising that ambiguity preferences did not differ between girls and boys. Namely, girls, on average, expected an amount of 10.76 winning colored ping-pong balls in this bag, whereas boys, on average, believed there were 9.80 winning colored ping-pong balls in this bag (Wilcoxon rank sum test, $p=0.03$ ). Based on their more optimistic outlook of winning colored ping-pong balls, one would expect that girls would be less ambiguity averse than boys.

In the full sample, we did not find an effect of age on our experimental variables (Table 3). When we focused on boys and girls separately, we found clear age differences in boys. Risk aversion decreased with age in boys (Jonckheere-Terpstra test, $p=0.022$ ), whereas we found a trend towards ambiguity aversion increasing with age in boys (Jonckheere-Terpstra test, $p=0.065$ ). Finally, beliefs decreased with age in boys (Jonckheere-Terpstra test, $p=0.014$ ). Except for the relationship between age and ambiguity aversion in boys, the other relationships also hold when we examine the correlation between age, as continuous variable, and risk $(r \tau=0.171, \mathrm{p}=0.040)$ and age, as continuous variable, and beliefs $(r \tau=0.151, \mathrm{p}=0.068)$, in boys.

\section{Result 3: Only in boys, risk aversion decreased with age.}

\section{Cognitive abilities}

In line with previous results on prudence and various measures of cognitive ability, our data showed a significant correlation between prudence and IQ score (Pearson's $\mathrm{r}=0.149, p=<0.05$, see Table A2 in the Appendix). However, we did not see a positive relationship between prudence and cognitive ability as reflected by the CRT. 
Table 3

Experimental variables by age and gender

\begin{tabular}{|c|c|c|c|c|c|}
\hline Variables & Sample & Mean & Std. dev. & Min & Max \\
\hline Experimental variables & Female & & & & \\
\hline Ambiguity & 83 & 0.039 & 0.108 & -0.211 & 0.367 \\
\hline Risk & 83 & 0.502 & 0.130 & 0.125 & 0.825 \\
\hline Beliefs & 83 & 10.760 & 3.218 & 2 & 16 \\
\hline Prudence & 83 & 4.024 & 1.115 & 0 & 5 \\
\hline Experimental variables & Male & & & & \\
\hline Ambiguity & 89 & 0.034 & 0.145 & -0.83 & 0.308 \\
\hline Risk & 89 & 0.506 & 0.118 & 0.025 & 0.950 \\
\hline Beliefs & 89 & 9.798 & 2.989 & 2 & 16 \\
\hline Prudence & 89 & 3.674 & 1.468 & 0 & 5 \\
\hline Experimental variables & Per age & & & & \\
\hline \multirow[t]{3}{*}{ Ambiguity } & $12-13 y(n=28)$ & 0.007 & 0.117 & -0.211 & 0.300 \\
\hline & $14-15 y(n=83)$ & 0.043 & 0.140 & -0.830 & 0.357 \\
\hline & $16-17 y(n=61)$ & 0.041 & 0.115 & -0.364 & 0.300 \\
\hline \multirow[t]{3}{*}{ Risk } & $12-13 y(n=28)$ & 0.543 & 0.119 & 0.275 & 0.775 \\
\hline & $14-15 y(n=83)$ & 0.498 & 0.129 & 0.025 & 0.950 \\
\hline & $16-17 y(n=61)$ & 0.494 & 0.117 & 0.225 & 0.825 \\
\hline \multirow[t]{3}{*}{ Beliefs } & $12-13 y(n=28)$ & 10.857 & 2.353 & 6 & 15 \\
\hline & $14-15 y(n=83)$ & 10.422 & 3.422 & 4 & 16 \\
\hline & $16-17 y(n=61)$ & 9.770 & 2.997 & 2 & 15 \\
\hline \multirow[t]{3}{*}{ Prudence } & $12-13 y(n=28)$ & 3.893 & 1.343 & 1 & 5 \\
\hline & $14-15 y(n=83)$ & 3.807 & 1.329 & 0 & 0.36 \\
\hline & $16-17 y(n=61)$ & 3.869 & 1.310 & 0 & 5 \\
\hline
\end{tabular}

\section{Result 4: Prudence and IQ scores were positively related.}

\section{Non-cognitive abilities}

Finally, components of non-cognitive abilities were related to risk and ambiguity aversion. As hypothesized, selfconfidence and risk aversion were negatively correlated, indicating that the more self-confident one is, the more risk tolerant (Pearson's $\mathrm{r}=-0.20, p=0.01$, see Table A2 in the Appendix). Furthermore, the personality measure for 'hard-working' and the parameter for ambiguity aversion were negatively related, indicating that the more one is willing to work, the more one is ambiguity tolerant (Pearson's $r=-0.15, p=<0.05$, see Table A2 in the Appendix). None of the non-cognitive abilities were related to prudence. ${ }^{11}$

Result 5: Components of personality - self-confidence and willingness to work hard - were negatively related to risk and ambiguity aversion.

\subsection{Robustness analyses}

We conducted a multivariate analysis to test the robustness of the bivariate correlations between our experimental variables and participants' demographic profile, while controlling for the order in which participants played the risk and ambiguous lottery (a dummy variable indicating 1 for ambiguous lottery first and 0 for risk lottery first) a dummy variable indicating if participants switched multiple times in the risk and/or ambiguous lottery (indicated by 1 or 0 when participants switched multiple times or not) and the classes in which the experiment took place.

The primary results outlined above remained qualitatively valid when we analyzed the models with these control variables: prudence was influenced by participants' IQ score, indicating a relationship between prudence and intelligence. Risk and self-confidence remained moderately related. Finally, participants' willingness to work hard influenced ambiguity preferences. The interaction between gender and age in all models specified in Table 4 is not significant, indicating that our reported pattern of decreasing risk aversion and beliefs for boys as they mature, should be evaluated cautiously.

All these results remained qualitatively valid in a smaller sample $(n=153)$ of participants who only switched once in the lotteries. Finally, when we analyzed the models with an ordered probit regression, the results remained qualitatively valid as well.

\section{Conclusion and discussion}

In this study, we examined the relationship between several individual variables - demographic, cognitive, and noncognitive - and the risk-taking behavior of a large group of adolescents, providing a comprehensive overview of how uncertainty is handled by this important, though understudied, population. In addition, we extended previous investigations

\footnotetext{
11 Using Holm's adjustment for multiple hypothesis testing (9 different measures of cognitive and non-cognitive abilities), the p value for the relationship between risk aversion and self-confidence becomes $\mathrm{p}=0.091$, between ambiguity aversion and work hard becomes $\mathrm{p}=0.394$, and between prudence and IQ score becomes $\mathrm{p}=0.459$.
} 
Table 4

OLS regression experimental variables

\begin{tabular}{|c|c|c|c|c|c|c|}
\hline \multirow[t]{2}{*}{$\begin{array}{l}\text { Dependent variables: } \\
\text { Independent variables: }\end{array}$} & \multicolumn{2}{|l|}{ Prudence } & \multicolumn{2}{|l|}{ Risk } & \multicolumn{2}{|l|}{ Ambiguity } \\
\hline & (1) & $(2)$ & (3) & (4) & (5) & (6) \\
\hline Prudence & & & $\begin{array}{l}0.006 \\
(0.007)\end{array}$ & $\begin{array}{l}0.004 \\
(0.007)\end{array}$ & $\begin{array}{l}0.014^{*} \\
(0.007)\end{array}$ & $\begin{array}{l}0.012 \\
(0.008)\end{array}$ \\
\hline Risk & $\begin{array}{l}0.792 \\
(0.890)\end{array}$ & $\begin{array}{l}0.552 \\
(0.926)\end{array}$ & & & $\begin{array}{l}-0.259 \\
(0.183)\end{array}$ & $\begin{array}{l}-0.291 \\
(0.193)\end{array}$ \\
\hline Ambiguity & $\begin{array}{l}1.598 \\
(0.838)\end{array}$ & $\begin{array}{l}1.379 \\
(0.894)\end{array}$ & $\begin{array}{l}-0.234^{* *} \\
(0.074)\end{array}$ & $\begin{array}{l}-0.275^{* * *} \\
(0.077)\end{array}$ & & \\
\hline Beliefs & $\begin{array}{l}0.010 \\
(0.034)\end{array}$ & $\begin{array}{l}-0.005 \\
(0.036)\end{array}$ & $\begin{array}{l}-0.003 \\
(0.003)\end{array}$ & $\begin{array}{l}-0.003 \\
(0.003)\end{array}$ & $\begin{array}{l}-0.004 \\
(0.003)\end{array}$ & $\begin{array}{l}-0.006^{*} \\
(0.003)\end{array}$ \\
\hline $14-15$ years & $\begin{array}{l}-0.364 \\
(0.424)\end{array}$ & $\begin{array}{l}-0.366 \\
(0.459)\end{array}$ & $\begin{array}{l}-0.029 \\
(0.038)\end{array}$ & $\begin{array}{l}-0.035 \\
(0.041)\end{array}$ & $\begin{array}{l}0.013 \\
(0.049)\end{array}$ & $\begin{array}{l}-0.004 \\
(0.052)\end{array}$ \\
\hline 16-17 years & $\begin{array}{l}-0.167 \\
(0.452)\end{array}$ & $\begin{array}{l}-0.247 \\
(0.629)\end{array}$ & $\begin{array}{l}-0.039 \\
(0.041)\end{array}$ & $\begin{array}{l}-0.044 \\
(0.056)\end{array}$ & $\begin{array}{l}0.017 \\
(0.045)\end{array}$ & $\begin{array}{l}-0.056 \\
(0.067)\end{array}$ \\
\hline Girls & $\begin{array}{l}0.436 \\
(0.516)\end{array}$ & $\begin{array}{l}0.337 \\
(0.528)\end{array}$ & $\begin{array}{l}-0.021 \\
(0.047)\end{array}$ & $\begin{array}{l}-0.032 \\
(0.047)\end{array}$ & $\begin{array}{l}-0.035 \\
(0.047)\end{array}$ & $\begin{array}{l}-0.060 \\
(0.050)\end{array}$ \\
\hline 14-15 years:girls & $\begin{array}{l}0.313 \\
(0.589)\end{array}$ & $\begin{array}{l}0.398 \\
(0.599)\end{array}$ & $\begin{array}{l}0.007 \\
(0.053)\end{array}$ & $\begin{array}{l}0.017 \\
(0.053)\end{array}$ & $\begin{array}{l}0.042 \\
(0.059)\end{array}$ & $\begin{array}{l}0.064 \\
(0.061)\end{array}$ \\
\hline $16-17$ years:girls & $\begin{array}{l}-0.090 \\
(0.610)\end{array}$ & $\begin{array}{l}0.025 \\
(0.626)\end{array}$ & $\begin{array}{l}0.032 \\
(0.055)\end{array}$ & $\begin{array}{l}0.039 \\
(0.056)\end{array}$ & $\begin{array}{l}0.013 \\
(0.058)\end{array}$ & $\begin{array}{l}0.048 \\
(0.061)\end{array}$ \\
\hline CRT & $\begin{array}{l}0.040 \\
(0.118)\end{array}$ & $\begin{array}{l}-0.008 \\
(0.125)\end{array}$ & $\begin{array}{l}0.016 \\
(0.011)\end{array}$ & $\begin{array}{l}0.015 \\
(0.011)\end{array}$ & $\begin{array}{l}-0.010 \\
(0.011)\end{array}$ & $\begin{array}{l}-0.010 \\
(0.012)\end{array}$ \\
\hline Dutch & $\begin{array}{l}0.252^{* *} \\
(0.149)\end{array}$ & $\begin{array}{l}-0.221 \\
(0.158)\end{array}$ & $\begin{array}{l}0.014 \\
(0.014)\end{array}$ & $\begin{array}{l}0.008 \\
(0.014)\end{array}$ & $\begin{array}{l}0.013 \\
(0.015)\end{array}$ & $\begin{array}{l}0.013 \\
(0.015)\end{array}$ \\
\hline Mathematics & $\begin{array}{l}0.089 \\
(0.103)\end{array}$ & $\begin{array}{l}0.076 \\
(0.107)\end{array}$ & $\begin{array}{l}-0.009 \\
(0.009)\end{array}$ & $\begin{array}{l}-0.004 \\
(0.009)\end{array}$ & $\begin{array}{l}-0.004 \\
(0.009)\end{array}$ & $\begin{array}{l}0.001 \\
(0.009)\end{array}$ \\
\hline IQ score & $\begin{array}{l}0.237^{* *} \\
(0.119)\end{array}$ & $\begin{array}{l}0.268^{* *} \\
(0.123)\end{array}$ & $\begin{array}{l}-0.012 \\
(0.011)\end{array}$ & $\begin{array}{l}-0.009 \\
(0.011)\end{array}$ & $\begin{array}{l}-0.002 \\
(0.012)\end{array}$ & $\begin{array}{l}-0.006 \\
(0.012)\end{array}$ \\
\hline Self-confidence & $\begin{array}{l}0.020 \\
(0.108)\end{array}$ & $\begin{array}{l}0.011 \\
(0.111)\end{array}$ & $\begin{array}{l}-0.018^{* *} \\
(0.010)\end{array}$ & $\begin{array}{l}-0.017^{*} \\
(0.009)\end{array}$ & $\begin{array}{l}-0.009 \\
(0.011)\end{array}$ & $\begin{array}{l}-0.006 \\
(0.011)\end{array}$ \\
\hline Motivation & $\begin{array}{l}-0.079 \\
(0.145)\end{array}$ & $\begin{array}{l}-0.061 \\
(0.149)\end{array}$ & $\begin{array}{l}-0.005 \\
(0.013)\end{array}$ & $\begin{array}{l}-0.003 \\
(0.013)\end{array}$ & $\begin{array}{l}-0.000 \\
(0.013)\end{array}$ & $\begin{array}{l}-0.002 \\
(0.013)\end{array}$ \\
\hline Work hard & $\begin{array}{l}0.062 \\
(0.119)\end{array}$ & $\begin{array}{l}0.073 \\
(0.123)\end{array}$ & $\begin{array}{l}0.015 \\
(0.011)\end{array}$ & $\begin{array}{l}0.014 \\
(0.011)\end{array}$ & $\begin{array}{l}-0.021^{*} \\
(0.011)\end{array}$ & $\begin{array}{l}-0.026^{* *} \\
(0.012)\end{array}$ \\
\hline Well-being & $\begin{array}{l}-0.017 \\
(0.131)\end{array}$ & $\begin{array}{l}0.004 \\
(0.133)\end{array}$ & $\begin{array}{l}-0.008 \\
(0.012)\end{array}$ & $\begin{array}{l}-0.008 \\
(0.012)\end{array}$ & $\begin{array}{l}0.008 \\
(0.011)\end{array}$ & $\begin{array}{l}0.010 \\
(0.011)\end{array}$ \\
\hline Controls & $\mathrm{N}$ & $\mathrm{Y}$ & $\mathrm{N}$ & $\mathrm{Y}$ & $\mathrm{N}$ & $\mathrm{Y}$ \\
\hline Constant & $\begin{array}{l}4.288 \\
(1.195)\end{array}$ & $\begin{array}{l}4.432 \\
(1.303)\end{array}$ & $\begin{array}{l}0.486 \\
(0.105)\end{array}$ & $\begin{array}{l}0.503 \\
(0.113)\end{array}$ & $\begin{array}{l}0.106 \\
(0.148)\end{array}$ & $\begin{array}{l}0.174 \\
(0.163)\end{array}$ \\
\hline Observations & 172 & 172 & 172 & 172 & 172 & 172 \\
\hline F-test & $\begin{array}{l}F(16,155)= \\
1.06\end{array}$ & $\begin{array}{l}\mathrm{F}(24,147)= \\
0.97\end{array}$ & $\begin{array}{l}F(16,155)= \\
1.98\end{array}$ & $\begin{array}{l}F(24,146)= \\
1.77\end{array}$ & $\begin{array}{l}F(16,155)= \\
1.66\end{array}$ & $\begin{array}{l}F(24,147)= \\
1.95\end{array}$ \\
\hline Prob $>F$ & 0.401 & 0.511 & 0.017 & 0.021 & 0.060 & 0.011 \\
\hline R-squared & 0.098 & 0.137 & 0.170 & 0.224 & 0.146 & 0.237 \\
\hline
\end{tabular}

***,*** significant at the $0.01,0.05,0.1$ level respectively. Note: Heteroskedasticity-corrected (robust) standard errors reported in parentheses for ambiguity model only. The variance of the residual in the models for risk and prudence were constant as tested by the Breusch Pagan test, and therefore standard errors are reported in parentheses.

by also examining the role of other dimensions of decision-making under uncertainty, namely ambiguity and prudence, in adolescence.

Overall, we found adolescents to be risk neutral, ambiguity averse, and prudent. Our description of adolescents' risk preferences aligns with some previous contributions surveyed in Sutter et al., 2019. There are relatively few studies on ambiguity preferences in this demographic group and although our finding that adolescents are ambiguity averse aligns with Sutter et al. (2013) and Borghans et al. (2009), it is at odds with the findings of both Tymula et al. (2012) and Li et al. (2015) who showed the opposite pattern of ambiguity tolerant adolescents. As there is evidence stressing that individual preferences for risk and ambiguity are highly dependent on the specific elicitation technique (Charness et al., 2013; Deck et al., 2013), this seems a likely explanation for these differences in results. Tymula et al. (2012) and Li et al. (2015) elicited partial ambiguity whereby only part of the unknown bag was revealed ${ }^{12}$, which is in contrast to our ambiguous setup where the unknown bag was completely unknown. Instead, we used the same procedure to elicit risk and ambiguity as did Sutter et al. (2013), showing consistent results of ambiguity aversion in adolescents.

\footnotetext{
12 Borghans et al. (2009) also had two urns (urns 2 and 3) with partial information about the composition of colored balls, but in determining ambiguity they only compared the risky urn (urn 1) with the fourth urn which content was completely unknown.
} 
While it is reassuring that our results for risk and ambiguity converged with other experimental studies that employed similar elicitation techniques, the ultimate goal is to identify adolescents' preferences for these aspects of uncertainty. The Ellsberg paradigm, which was used in this experiment, is a standard elicitation technique to measure individuals' ambiguity preferences. Ellsberg urn experiments are transparent, easily implemented, and truly capture preferences regarding unknown probabilities (Trautmann and van de Kuilen, 2015, p. 94). Therefore, this paradigm has been used in many experimental studies on ambiguity with non-adolescent samples (Trautmann and van de Kuilen, 2015). The majority of these studies reported risk and ambiguity aversion (Trautmann and van de Kuilen, 2015). Based on our results, we can conclude that adolescents dislike ambiguity, as do adults. However, adolescents' CEs for the risky prospect were in accordance with the expected value of the risky prospect, and thus they cannot be characterized as risk averse, which is commonly found in adults.

For prudence, the data here provide a new, and important, observation that prudence is already distinguishable at a relatively young age. Moreover, the absence of correlation between risk aversion and prudence supports the idea, set out by Crainich et al. (2013, p. 1534), that prudence is a universal trait which is present across the risk spectrum.

After characterizing adolescents' attitudes towards our three measures of decision-making under uncertainty, we investigated the relationships with the following four specific individual variables: gender, age, cognitive and non-cognitive abilities.

We only found subtle age effects in adolescent males, otherwise age as a demographic factor did not affect decisionmaking under uncertainty. With regard to the demographic category of gender, the only notable gender difference we found was a difference in beliefs regarding the ambiguous lottery: girls expressed more optimistic beliefs, though interestingly did not act upon these beliefs by exhibiting greater ambiguity tolerance. Girls and boys did not differ on any of the noncognitive abilities, however one speculation is that girls hold less confidence in their stated beliefs and therefore are not willing to express more ambiguity seeking behavior. The most surprising effect with regard to gender was its null effect on our population's risk preferences. Most studies, as surveyed in Sutter et al. (2019), found boys to be more risk seeking than girls. In adults, a majority of studies also illustrated that women are more risk averse than men (Croson and Gneezy, 2009). However, in their work on global preferences, Falk et al. (2018) showed that 16 out of 76 countries did not show evidence of a gender effect on risk preferences and Eckel and Grossman (2008) also stressed that "there is enough counterevidence to warrant caution" (p. 1071). One of the complicating factors they address is the lack of comparability across studies. Experimental setups differ tremendously, leading to differences in behavior and the effect of moderators such as gender. Nevertheless, the Ellsberg setup we used was also used in Sutter et al. (2013), which found that boys were more risk seeking than girls. One potential explanation we can offer here is that the high school in our study is at the highest academic level in the Netherlands, potentially implying that the cognitive ability across genders is relatively homogenous. For instance, math grades did not differ between girls and boys in our sample either. As evidence shows that the school environment is very important for the existence or absence of gender differences in risk (Booth and Nolen, 2012), the school environment in our study may well have created a sense of equality, which minimized any subsequent differences in risk between girls and boys.

In addition to age and gender, we also examined participants' cognitive and non-cognitive abilities. Only recently have economic studies considered these variables relevant for decision-making (Borghans et al., 2008), and indeed there has been some evidence that this characteristic can influence prudence in adults (Noussair et al., 2014; Breaban et al, 2016). Here, we also found that prudence and intelligence were positively correlated in adolescence, though notably intelligence did not correlate with either risk or ambiguity aversion. Therefore, this finding supports the view that prudence is particularly evident among people with high education levels (Noussair et al., 2014, p. 345). Theoretical predictions (Kimball, 1990) as well as the empirical results of Noussair et al. (2014) stress the importance of prudence for precautionary saving behavior. Sutter et al. (2013) have previously found a positive correlation between intelligence and saving behavior in an adolescent population, and therefore it might well be that prudence is one of the underlying explanatory drivers for this. Future studies could usefully focus on directly relating the prudent attitudes of adolescents to their actual saving behavior.

Finally, we looked at adolescents' non-cognitive abilities via a school-taken questionnaire. Our finding here that adolescents who reported less self-confidence were more risk averse lines up to previous work on the relationship between neuroticism and risk preferences (Borghans et al., 2009; Rustichini et al., 2016; Becker et al., 2012), albeit in this new age group. Furthermore, we found that the willingness to work hard was related to adolescents' ambiguity preferences.

Taken together, in addition to studying gender and age, cognitive and non-cognitive abilities provide a much more refined characterization of adolescents' attitude towards risk, ambiguity, and prudence. Importantly, this can be of enormous help in targeting policy to specific sub-groups of adolescents. Let us give two examples. Firstly, (extreme) prudent behavior could affect adolescents' educational choices as they will soon experience a transition from high school to college. As prudence is especially prevalent amongst those of higher levels of intelligence, they are likely to pursue a longer than average educational trajectory and usually rely on some form of funding to finance their studies. Investing in higher-level education is risky in the sense that it is unknown if these investments will pay out down the road. This background risk might prove more difficult for the prudent student to overcome when choosing student loans as a way to finance their education. Interestingly, Eckel et al. (2007) has shown that Canadian students who have experience with carrying and managing debt are more willing than others to take on additional debt to finance postsecondary education, thus reinforcing the possibility that more prudent individuals may be in danger of making a lack of educational investment in their own future. Furthermore, students, who are reluctant to take on debt more frequently choose to work part-time, to opt for a lower cost institution, or 
to study part-time (Institute for Higher Education Policy, 2008). These are all factors that increase the risk of study dropout, and ironically may be more present in more prudent students. A follow-up study could usefully test if prudence is prevalent in those students who borrow the least, demonstrating a direct relationship between this higher-order risk attitude and reallife behavior. Secondly, based on our findings, self-confident adolescents are more risk tolerant and therefore more likely to engage in harmful risky activities. Teaching a variety of non-cognitive skills - such as time management, goal attainment, and self-reflection - in disadvantaged youth during high school has shown promise in increasing college enrollment and reducing arrest rates (Kautz and Zanoni, 2014). Including awareness of adolescents' own levels of self-confidence as part of their self-reflection could usefully be adopted.

In sum, this study examined relationships between several individual factors and adolescents' attitudes towards risk, ambiguity, and prudence. These characterizations can aid in better policy design to protect adolescents from engaging in harmful risky activities, and to more optimally guide their future educational and employment choices.

\section{Acknowledgements}

We would like to thank our two excellent research assistents Judith Strunk and Jesse Fenneman with their help in collecting the data. We are very thankful for Stedelijk Gymnasium Nijmegen with their willingness to cooperate with our research. This research was partially supported by a European Research Council grant to Alan Sanfey (ERC StG 313454).

\section{Supplementary materials}

Supplementary material associated with this article can be found, in the online version, at doi:10.1016/j.jebo.2020.03.028.

\section{References}

Akay, A., Martinsson, P., Medhin, H., Trautmann, S., 2012. Attitudes toward uncertainty among the poor: an experiment in rural Ethiopia. Theory and Decision $73,453-464$

Almlund, M, Duckworth, AL, Heckman, JJ, Kautz, T., 2011. Personality psychology and economics. In: Hanushek, EA, Machin, S, Wößmann, L (Eds.), Handbook of the Economics of Education, 4. Elsevier, Amsterdam, pp. 1-181.

Baillon, A., 2017. Prudence with respect to ambiguity. The Economic Journal 127 (604), 1731-1755.

Becker, A., Deckers, T., Dohmen, T., Falk, A., Kosse, F., 2012. The relationship between economic preferences and psychological personality measures. Annual Review of Economics 4 (1), 453-478.

Blum, R., Nelson-Mmari, K., 2004. The health of young people in a global context. Journal of Adolescent Health 35, 402-418.

Booth, A.L., Nolen, P., 2012. Gender differences in risk behaviour: does nurture matter? The economic journal 122 (558), F56-F78.

Borghans, L., Duckworth, A.L., Heckman, J.J., Ter Weel, B., 2008. The economics and psychology of personality traits. Journal of human Resources 43 (4), 972-1059.

Borghans, L., Heckman, J.J., Golsteyn, B.H., Meijers, H., 2009. Gender differences in risk aversion and ambiguity aversion. Journal of the European Economic Association 7 (2-3), 649-658.

Borghans, L., Golsteyn, B.H., Heckman, J.J., Humphries, J.E., 2016. What grades and achievement tests measure. Proceedings of the National Academy of Sciences 113 (47), 13354-13359.

Breaban, A., van de Kuilen, G, Noussair, CN., 2016. Prudence, Emotional State, Personality, and Cognitive Ability. Frontiers in Psychology 7, 1688.

Browning, Martin, Lusardi, Annamaria, 1996. Household Saving: Micro Theories and Micro Facts. Journal of Economic Literature 34 (4), $1797-1855$.

Cárdenas, J.C., Dreber, A., Von Essen, E., Ranehill, E., 2012. Gender differences in competitiveness and risk taking: Comparing children in Colombia and Sweden. Journal of Economic Behavior \& Organization 83 (1), 11-23.

Chandler, D., Levitt, S.D., List, J.A., 2011. Predicting and preventing shootings among at-risk youth. American Economic Review 101 (3), $288-292$.

Charness, G., Gneezy, U., Imas, A., 2013. Experimental Methods: Eliciting Risk Preferences. Journal of Economic Behavior \& Organization 87, 43-51.

Crainich, D., Eeckhoudt, L., Trannoy, A., 2013. Even (mixed) risk lovers are prudent. American Economic Review 104, 1529-1535.

Croson, R., Gneezy, U., 2009. Gender differences in preferences. Journal of Economic literature 47 (2), $448-474$.

Cubitt, R., van de Kuilen, G., Mukerji, S., 2012. Sensitivity Towards Ambiguity: A Qualitative Test and Measurement, University of Oxford. Working paper.

Deck, C., Lee, J., Reyes, J.A., Rosen, C.C., 2013. A failed attempt to explain within subject variation in risk taking behavior using domain specific risk attitudes. Journal of Economic Behavior \& Organization 87, 1-24.

Deck, C., Schlesinger, H., 2010. Exploring higher order risk effects. Review of Economic Studies 77, 1403-1420.

Deck, C., Schlesinger, H., 2014. Consistency of higher-order risk preferences. Econometrica 82 (5), $1913-1943$.

Deckers, T., Falk, A., Kosse, F., Schildberg-Horisch, H., 2015. How does socioeconomic status shape a childs personality? Technical report, IZA Discussion Paper.

Defoe, I.N., Dubas, J.S., Figner, B., van Aken, M.A., 2015. A meta-analysis on age differences in risky decision making: Adolescents versus children and adults. Psychological Bulletin 141, 48-84

Dohmen, T., Falk, A., Huffman, D., Sunde, U., 2010. Are risk aversion and impatience related to cognitive ability? American Economic Review 100 (3), $1238-1260$.

Ebert, S., Wiesen, D., 2011. An Experimental methodology testing for prudence and third-order preferences. Management Science 57, $1334-1349$.

Ebert, S., van de Kuilen, G., 2017. Measuring Multivariate Risk Preferences. Tilburg University, Tilburg, the Netherlands Working paper.

Eckel, C.C., Grossman, P.J., 2008. Men, women and risk aversion: Experimental evidence. Handbook of experimental economics results 1, 1061-1073.

Eckel, C.C., Grossman, P.J., Johnson, C.A., de Oliveira, A.C., Rojas, C., Wilson, R.K., 2012. School environment and risk preferences: Experimental evidence. Journal of Risk and Uncertainty 45 (3), 265-292.

Eckel, C.C., Johnson, C., Montmarquette, C., Rojas, C., 2007. Debt aversion and the demand for loans for postsecondary education. Public Finance Review 35 (2), 233-262

Eeckhoudt, L., Schlesinger, H., 2006. Putting Risk in Its Proper Place. American Economic Review 96, 280-289.

Ellsberg, D., 1961. Risk, ambiguity, and the Savage axioms. Quarterly Journal of Economics 75, 643-669.

Falk, A., Becker, A., Dohmen, T., Enke, B., Huffman, D., Sunde, U., 2018. Global evidence on economic preferences. The Quarterly Journal of Economics 133 (4), 1645-1692

Fehr, E., Goette, L., 2005. Robustness and Real Consequences of Nominal Wage Rigidity. Journal of Monetary Economics 52 (4), $779-804$.

Frederick, S., 2005. Cognitive reflection and decision making. Journal of Economic Perspectives 19 (4), 25-42.

Haering, A., Heinrich, T., Mayrhofer, T., 2017. Exploring the Consistency of Higher-Order Risk Preferences. Ruhr Economic Papers 688 Working paper. 
Harbaugh, W.T., Krause, K., Vesterlund, L., 2002. Risk Attitudes of Children and Adults: Choices over Small and Large Probability Gains and Losses. Experimental Economics 5 (1), 53-84.

Heckman, J.J., Mosso, S., 2014. The economics of human development and social mobility. Annual Review of Economics 6 (1), $689-733$.

Heinrich, T., Shachat, J., 2018. The Development of Risk Aversion and Prudence in Chinese Children and Adolescents. Durham University, Mimeo.

Hogarth, R.M., Villeval, M.C., 2014. Ambiguous incentives and the persistence of effort: Experimental evidence. Journal of Economic Behavior \& Organization $100,1-19$.

Human Mortality Database, 2017. Human mortality database. University of California; and Rostock, BerkeleyGermany Max Planck Institute for Demographic Research. Retrieved from www.mortality.org or www.humanmortality.de.

Kautz, T., Heckman, J.J., Diris, R., Ter Weel, B., Borghans, L., 2014. Fostering and measuring skills: Improving cognitive and non-cognitive skills to promote lifetime success (No. w20749). National Bureau of Economic Research.

Kautz, T., Zanoni, W., 2014. Measuring and fostering non-cognitive skills in adolescence. Evidence from Chicago Public Schools and the OneGoal Program. University of Chicago, Chicago, IL.

Keynes, G.M., 1921. A treatise on probability. MacMillan Co, London.

Kimball, M.S., 1990. Precautionary Saving in the Small and in the Large. Econometrica 58 (1), 53-73.

Knight, F.H., 1921. Risk, uncertainty and profit. Houghton Mifflin, Boston.

Lehwald, G., 1985. Zur Diagnostik des Erkenntnisstrebens bei Schülern. Volk und Wissen, Berlin.

Levin, I.P., Hart, S.S., Weller, J.A., Harshman, L.A., 2007. Stability of Choices in a Risky Decision-Making Task: A 3-Year Longitudinal Study with Children and Adults. Journal of Behavioral Decision Making 20 (3), 241-252.

Levin, I.P., Hart, S.S., 2003. Risk preferences in young children: Early evidence of individual differences in reaction to potential gains and losses. Journal of Behavioral Decision Making 16 (5), 397-413.

Li, R., Brannon, E.M., Huettel, S.A., 2015. Children do not exhibit ambiguity aversion despite intact familiarity bias. Frontiers in psychology 5, 1519.

Liepmann, D., Beauducel, A., Brocke, B., Amthauer, R., 2007. Intelligenz-Struktur-Test 2000 R (I-S-T 2000 R) Göttingen: Hogrefe.

Maier, J., Rüger, M., 2011. Higher Order Risk Preferences: an Experimental Investigation. University of Hamburg Working Paper.

Munro, A., Tanaka, Y., 2014. Risky rotten kids: An experiment on risk attitudes amongst adolescents in rural Uganda. GRIPS Discussion Papers 14-01. National Graduate Institute for Policy Studies.

National Institute for Budget Information (Nibud), 2016. Nibud School students' research: the Netherlands. Retrieved from: https://www.nibud.nl/ wp-content/uploads/Nibud-scholierenonderzoek_2016.pdf

Noussair, C., Trautmann, S.T., van de Kuilen, G., 2014. Higher order risk attitudes, demographics, and financial decisions. Review of Economic Studies 81, $325-355$.

Pedroni, A., Frey, R., Bruhin, A., Dutilh, G., Hertwig, R., Rieskamp, J., 2017. The risk elicitation puzzle. Nature Human Behaviour 1 (11), 803.

Remund, A., Camarda, C.G., Riffe, T., 2018. A cause-of-death decomposition of young adult excess mortality. Demography 1-22.

Rothschild, M., Stiglitz, J.E., 1970. Increasing Risk: I. A Definition. Journal of Economic Theory 2 (3), $225-243$.

Rustichini, A., DeYoung, C.G., Anderson, J.E., Burks, S.V., 2016. Toward the integration of personality theory and decision theory in explaining economic behavior: An experimental investigation. Journal of Behavioral and Experimental Economics 64, 122-137.

Smits, J.A.E., Vorst, H.C.M., 2008. School Vragen Lijst voor basisonderwijs en voortgezet onderwijs. Pearson, Amsterdam.

Steinberg, L., 2004. Risk-taking in adolescence: What changes, and why? Annals of the New York Academy of Sciences 1021, 51-58.

Sutter, M., Kocher, M.G., Rützler, D., Trautmann, S.T., 2013. Impatience and uncertainty: Experimental decisions predict adolescents' field behavior. American Economic Review 103 (1), 510-531.

Sutter, M., Zoller, C., Glätzle-Rützler, D., 2019. Economic behavior of children and adolescents - A first survey of experimental economics results. European Economic Review 111, 98-121.

Tarazona-Gomez, M., 2004. Are individuals prudent? An experimental approach using lottery choices. In: Working paper, Copenhagen Business School

Trautmann, S.T., van de Kuilen, G., 2018. Higher order risk attitudes: A review of experimental evidence. European Economic Review 103, 108-124.

Trautmann, S.T., van de Kuilen, G., 2015. In: Keren, G., Wu, G. (Eds.). Blackwell Handbook of Judgment and Decision Making, pp. 89-116.

Tversky, A., Kahneman, D., 1992. Advances in prospect theory: Cumulative representation of uncertainty. Journal of Risk and uncertainty 5 (4), 297-323.

Tymula, A., Rosenberg Belmaker, L.A., Roy, A.K., Ruderman, L., Manson, K., Glimcher, P.W., Levy, I., 2012. Adolescents' risk-taking behavior is driven by tolerance to ambiguity. In: Proceedings of the National Academy of Sciences of the United States of America, 109, pp. 17135-117140.

Wakker, P.P., 2010. Prospect theory for risk and ambiguity. Cambridge University Press, Cambridge.

Williams, P., Holmbeck, G., Greenley, R., 2002. Adolescent health psychology. Journal of Consulting and Clinical Psychology 70 (3), 828. 